\title{
O CETICISMO INACABADO DE DESCARTES ${ }^{*}$
}

\author{
Marcos César Seneda **
}

\section{RESUMO}

Este texto pretende mostrar que, do ponto de vista das ciências empíricas, o projeto de demolição do ceticismo, conduzido por Descartes, perdura até a VI Meditação e nela não pode ser concluído. Se isto assim ocorre, é porque há dois modelos de superação do ceticismo em Descartes. O primeiro modelo diz respeito à superação da dúvida metafísica. Esse modelo alcança algum êxito já na II Meditação, na qual, por analogia com o procedimento matemático, a descoberta de uma evidência irrecusável conduz à primeira certeza, e esta se torna o ponto de partida para a obtenção de outras. O segundo modelo diz respeito à superação da dúvida sobre os conteúdos do mundo sensível. Embora pareça que a solução do segundo modelo decorra diretamente do êxito obtido no domínio do primeiro, isto não se dá, porque, conquanto Descartes construa os fundamentos matemáticos de uma teoria do extenso, nela não consegue resolver os problemas da Física entendida como uma teoria dos objetos empíricos.

Palavras-chave: Descartes. Ceticismo. Dúvida. Física. Matemática.

\begin{abstract}
The intention of this text is to show that from the point of view of the

\footnotetext{
* Este texto apresenta o resultado parcial de um trabalho realizado com o auxílio da Fapemig - Fundação de Apoio à Pesquisa de Minas Gerais.

** Professor Adjunto 4 do Instituto de Filosofia (IFILO) da Universidade Federal de Uberlândia.E-mail: mseneda@ufu.br
} 
empirical sciences, the project of demolition of skepticism, conducted by Descartes, continues up to Meditation VI and may not be concluded in it. If this occurs, it is because there are two models of overcoming skepticism in Descartes. The first model is in regard to overcoming the metaphysical doubt. This model is already somewhat successful in Meditation II in which, by analogy with the mathematical procedure, the discovery of evidence that cannot be refused leads to the first certainty, and this becomes the point of departure for the obtaining of others. The second model is in regard to overcoming doubt about the content of the sensible world. Although it may seem that the solution of the second model comes to pass directly from the success obtained in the mastery of the first, this is not so, because although Descartes constructs the foundations of mathematics from a theory of extension, he is not able to resolve in it the problems of Physics understood as a theory of empirical objects.

Keywords: Descartes. Skepticism. Doubt. Physics. Mathematics.

\section{I}

Este texto procura examinar se a solução metafísica encontrada por Descartes para fundamentar a Matemática pode ser também considerada suficiente para fundamentar a Física. Resumidamente, a reflexão aqui apresentada percorre os seguintes passos. A) Descartes procura estabelecer uma fundamentação absoluta do saber. a') Como associa o sensível ao provável, Descartes recusa qualquer ponto de partida que principie dos sentidos. a") Recusa igualmente o modelo da validade empírica, a partir do qual se possa demarcar, por análise e regressivamente, os fundamentos de uma ciência. B) Recorre, portanto, a uma dupla fundamentação metafísica do conhecimento. b') As coisas sensíveis possuem uma tênue realidade objetiva. b") Somente as ideias matemáticas, não sensíveis, possuem evidência suficiente para assegurar a fundamentação do conhecimento. C) Desse modo, permanece insolúvel o déficit 
ontológico. c') É possível assegurar, por evidência, a aderência entre a Matemática e o extenso. c") Mas como assegurar a congruência entre a Matemática e os sentidos, que funda o domínio da Física? D) A partir dessa questão, será examinado o modo como Descartes acolhe o projeto cético. d.) Nesse sentido, há que se perguntar se Descartes consegue superar a posição cética que se abre com a I Meditação. d') E há que se perguntar, igualmente, se as certezas posteriormente descobertas delimitam o ceticismo sobre o mundo externo como um hiato, que se posiciona na antecâmara do percurso da fundamentação, ou se o ceticismo tem forças para permanecer subjacente no trajeto meditativo. Em suma, há que se perguntar se o sistema cartesiano supera o projeto cético ou convive com ele. ${ }^{1}$

Levantamos aqui a seguinte hipótese, que será o fio condutor desse trabalho: o preço a se pagar por uma fundamentação absoluta do saber é tão alto, que a dívida não poderá ser resgatada por inteiro, por conseguinte, o sistema será obrigado a conviver, lado a lado, com um lócus de certeza e com um lócus de incerteza, ou seja, entre os graus de

\footnotetext{
${ }^{1}$ A posição mais tradicional, sobre a relação entre Descartes e o ceticismo, é bem retratada por R. H. Popkin, quando observa: "Ademais, a refutação do ceticismo por Descartes fez os céticos voltarem seus ataques contra seu sistema, ao invés de os voltarem contra seus tradicionais inimigos. Portanto, os argumentos céticos tiveram de ser alterados para enquadrar o novo oponente, e o ceticismo, na última metade do século XVII, deixou de ser anti-escolástico e anti-platônico, para tornar-se anticartesiano" (1979, p. XVIII). Conquanto o autor reavalie essa posição no decorrer de sua reflexão (POPKIN, 1979, p. 193-213), e seja objetivo deste texto também reavaliá-la, é fato que Descartes pretendia superar o projeto cético e que sua obra foi assim compreendida por todos aqueles que o circundavam. Já que Descartes acolhe confiante o ceticismo no interior de sua reflexão, assim como os troianos receberam um cavalo de madeira como signo de uma batalha já vencida, torna-se, então, importante indagar acerca da suposta fragilidade do ceticismo no interior da reflexão cartesiana, ou seja, cumpre examinar se o ceticismo sucumbe após a I Meditação ou se ele permanece residualmente do decorrer das seis Meditações. Como aqui optou-se pela segunda alternativa, trata-se, portanto, de examinar a obra contra as intenções explícitas do próprio autor.
} 
perfeição das ideias matemáticas e os graus de incerteza das ideias advindas do mundo empírico haverá sempre uma insuperável incongruência.

\section{II}

Para examinarmos esse problema, principiemos com a dúvida metódica da I Meditação, especialmente com o passo em que Descartes examina as ciências que lançam mão de construções que operam com a composição do empírico e do matemático. Primeiro situemos essa passagem. Após o argumento do sonho, em que opera com a indistinção do índice de realidade que separa o mundo imaginário do mundo real, Descartes vale-se do modelo do pintor. Esse modelo torna-se propício porque, ao examinar o modelo onírico e constatar o problema da indistinção entre sonho e vigília, o autor aloca-se no imaginário e aí se defronta com um problema central da teoria da verdade: a similitude e a remissão. Descartes percebe que não consegue conter o mundo imaginário dentro de si mesmo, porque os seus conteúdos mais simples parecem remeter para "fora". Há uma força irredutível em suas representações, que parecem se referir a conteúdos que não conseguimos suprimir.

Para examinar esse problema da similitude e da remissão, Descartes vai adotar dois procedimentos. Em primeiro lugar, vai decompor os conteúdos da imaginação, para saber se há algum componente do mundo imaginário que não remete ao mundo real captado pelos sentidos. Em segundo lugar, vai decompor o fictício até encontrar o simples, com vistas a examinar se o simples não pode ser posto em dúvida, e com o intuito de investigar se o simples, localizado no imaginário e sendo indubitável, remeteria também a algo simples no mundo real, que poderia ser o fundamento sólido de uma primeira verdade, sobre a qual outras se construiriam. As operações que um pintor executa servem então de modelo para o exame do que caracteriza o mundo imaginário. Esse pintor

a) pode operar com imagens reproduzidas diretamente dos sentidos, que sempre remetem a um mundo externo; 
b) pode operar com imagens fictícias (sereia, quimera, cavalo alado), que, no entanto, se forem decompostas em suas partes simples, podem ser todas encontradas no mundo colhido pelos sentidos;

c) pode ainda compor algo não figurativo. Nesse caso, remanescem ainda as cores, que "[...] devem ser, porém, verdadeiras" (AT, VII, p. 20 - FC, I Méd., §6)2.

Em todos esses exemplos, a força do mundo externo se manifesta no vetor de remissão. Descartes percebe que não há nada no mundo da imaginação que não tenha sido presenciado no mundo advindo dos sentidos. Logo, o mundo da imaginação não tem um fundamento distinto do mundo dos sentidos. Desse modo, não basta, por decomposição, encontrar o simples no imaginário, é preciso examinar se, conexo ao simples, não há algo, em sua origem, radicalmente distinto das imagens advindas do mundo dos sentidos. Do contrário, se o todo dos produtos da imaginação for extraído integralmente do todo advindo dos sentidos, não há como avançar mais passo algum no percurso dessa I Meditação.

$\mathrm{O}$ auge dessa acrobacia, que possibilita ao autor separar-se do mundo dos sentidos e recolher-se no interior do pensamento, encontra-se na antecâmara da dúvida extremada, a qual, para poder ser ampliada, necessitará de uma intervenção externa, mas empreendida de um ponto

\footnotetext{
${ }^{2}$ A referência usada para os textos de Descartes é a edição Adam et Tannery (Oeuvres de Descartes, publiées par Charles Adam et Paul Tannery, 11 volumes, Paris, Vrin, 1996). Na notação simplificada usada internacionalmente, AT indica a edição; os numerais romanos, o volume; e os algarismos arábicos, o número da página. O texto das Meditações sobre Filosofia Primeira será aqui citado a partir da tradução de Fausto Castilho (FC), feita diretamente do latim e publicada pela Editora da Unicamp (DESCARTES, 2004). Assim, junto à paginação da edição Adam \& Tannery (AT - DESCARTES, 1996), virá a referência da edição Fausto Castilho, cujo localizador será a Meditação e o parágrafo respectivo. Conforme observa o tradutor, essa edição contém, interpoladas no texto em português, as adições que Descartes fez quando leu a obra na tradução francesa de De Luynes, as quais foram aqui marcadas com itálico. Salvo o artigo de J.-M. Beyssade, os demais textos encontrados nas referências bibliográficas foram traduzidos pelo autor da presente contribuição.
} 
de vista metafísico. ${ }^{3}$ Antes dessa intervenção, prosseguindo no percurso agora da análise e não meramente da dúvida, Descartes descobre no interior do pensamento uma parte do pensamento que não tem similitude com o mundo dos sentidos, mas da qual depende a própria natureza do imaginário. Analogicamente, assim como o pintor é forçado a operar com as cores, se pretendo operar com o que é próprio às imagens, sou forçado a me remeter ao extenso, às figuras e aos números.

Ora, ao prosseguir no trajeto da análise, Descartes descobre uma radical distinção ontológica que está na base da natureza dos compostos. E é esta distinção radical que nos interessa aqui, porque ela reenvia os compostos, em virtude de sua própria constituição, para a região das coisas duvidosas. Acerca disso, Descartes afirma:

[...] a Física, a Astronomia, a Medicina e todas as outras disciplinas que dependem da consideração das coisas compostas são, na verdade, duvidosas, ao passo que a Aritmética, a Geometria e outras desse modo - que não tratam senão de coisas muito simples e muito gerais, pouco se preocupando com que estejam ou não na natureza das coisas - contêm algo certo e fora de dúvida. Pois, esteja eu acordado ou dormindo, dois e três juntos são cinco e o quadrado não tem mais que quatro lados (AT, VII, p. 20 - FC, I Med., §8).

\footnotetext{
${ }^{3}$ Se se trata de um auge, isso ocorre porque, prosseguindo na análise, Descartes defronta-se com um lócus de evidência, que, mediante as forças de seu intelecto, não consegue mais recusar. Mas é preciso examinar esse lócus de evidência, para saber se, reivindicado como fundamento, ele resiste às construções que devem a ele se sobrepor. J.-L. Poirier comenta: “A idéia vertiginosamente profunda de Descartes, nesse passo, é que a própria racionalidade deve ser fundada. Uma racionalidade não criticada, espontânea, não vale mais do que a submissão cega ao sensível: um racionalismo irrefletido é, no fundo, um preconceito como qualquer outro. Indo além de nossas certezas, não somente naturais, mas racionais, a interrogação torna-se metafisica" (1987, p. 106). É preciso, portanto, recorrer a um poder superior e exterior aos recursos próprios, que possibilite, mediante um procedimento metafísico, examinar o grau de certeza que pode ser alcançado pelo cogito.
} 
Esta passagem é muito instrutiva, pelas seguintes razões. Primeira, é o próprio Descartes que faz uma classificação ontológica das ciências, separando as que dependem da consideração dos compostos e as que tratam somente de coisas muito simples e gerais. Segunda, essa separação ontológica dá-se a partir dos níveis de evidência que, por assim dizer, cada grupo de ciências comporta. Terceira, mesmo as ciências que operam por conjunção do extenso com o empírico, ou seja, que constroem seus objetos em associação direta com a Matemática, ainda assim não conseguem se retirar do terreno das coisas duvidosas. Se isso ocorre é porque dependem da conjunção de dois níveis de evidência, e precisam jungir as ciências dos simples, que operam diretamente sobre um nível ótimo de evidência presente ao intelecto, e as ciências dos compostos, que precisam transpor os sentidos para encontrar, indiretamente, seus supostos objetos. ${ }^{4}$ Quarta, se essa leitura é coerente, é porque o encontro com o simples, no trajeto da decomposição, e a descoberta de uma evidência, nesse mesmo trajeto, referem-se a procedimentos que nem sempre se recobrem. O exame promovido pela ampliação da dúvida não é somente físico, mas metafísico, ou seja, não se trata de meramente decompor a representação empírica em suas partes mínimas ou simples, mas de encontrar o simples que não remeta a uma fonte de evidência como a sensação, que é obscura. Por isso há um desnível ontológico, porque, enquanto simples, a extensão, a grandeza e o número não se reportam a nenhum dado simples alcançável no mundo externo, mas se remetem a um referente que está ao alcance exclusivo do intelecto. Assim, nessa passagem sobre a natureza dos compostos, que constitui uma antecâmara da dúvida metafísica, presenciamos uma ruptura

\footnotetext{
${ }^{4}$ Se esta passagem é instrutiva, como dissemos, é porque aqui, já na I Meditação e em contraposição à VI Meditação, o próprio autor nos chama a atenção para a existência de um desnível ontológico entre as ciências que tratam dos simples e aquelas que precisam considerar os compostos. Isso indica que a descoberta de níveis de certeza não elimina, por procedimentos metodológicos - como a observação da ordem das razões -, os graus de indefinição de objetos que estão inscritos em um outro nível ontológico.
} 
paradoxal. ${ }^{5}$ Por um lado, saímos da oposição entre o imaginário e a realidade, porque descobrimos uma região mais fundamental, em que a similitude com o externo não é critério de verdade. Mesmo que desapareça o mundo dos sentidos, essas representações não deixam de ser menos verdadeiras. Se isso ocorre, é porque o grau de verdade (aqui idêntico à certeza) que elas contêm independe da remissão ao mundo externo. Por outro lado, conquistados esses graus de certeza, já não consigo transportálos de volta para o mundo externo, porque, em virtude de sua estrutura ontológica, este já não consegue comportar aqueles graus de certeza a não ser parcial e imperfeitamente.

Por conseguinte, por maior que seja a realidade objetiva das ideias matemáticas, elas nunca têm acesso direto à região das coisas corpóreas. A Física, em Descartes, é sempre definida pela aplicação das ideias matemáticas ao extenso, e esta aplicação, do ponto de vista das ciências empíricas, deveria poder referir-se de modo válido à imagem sensível das coisas corporais, captadas pelo corpo próprio. Eis o grande problema cartesiano, já anunciado, como vimos, na I Meditação, e que se encontra no fundamento da Física: essa imagem sensorial captada pelo corpo próprio é sempre deficitária, e as ideias matemáticas devem se aplicar a essa imagem

\footnotetext{
${ }^{5}$ Se o processo dubitativo sofre uma interrupção marcante em face das ideias matemáticas, é porque há aqui uma diferença de níveis ontológicos entre o simples supostamente acessível aos sentidos por decomposição e o simples acessível mentalmente através das ideias matemáticas. M. Gueroult comenta: "Pois, se eu não posso duvidar naturalmente das noções matemáticas, é porque delas está ausente a condição que torna possível a dúvida, a saber, a composição. A impossibilidade de duvidar se funda aqui sobre a natureza do objeto oferecido ao pensamento, e a certeza retorna a esse objeto" (1968, p. 40). Talvez fosse mais preciso afirmar que, no campo matemático, o simples (porque há objetos matemáticos complexos) é destituído não só de todo tipo de composição, mas também de todo tipo de remissão ao mundo externo. Por isso podemos afirmar que o simples, no âmbito matemático, difere do simples descoberto por decomposição no âmbito dos sentidos, porque se encontram em distintos níveis ontológicos. O simples, no âmbito matemático, remete a si, por isso lhe pertence um índice de certeza que não pode ser subjugado pela dúvida, a não ser que se recorra à hipótese metafísica da intervenção externa.
} 
sensorial. Ou seja, não há possibilidade alguma, de um lado, de as ideias matemáticas transporem as imagens sensoriais das qualidades secundárias e de encontrarem diretamente os corpos externos, que supostamente se defrontam com os meus sentidos. De outro lado, não há também possibilidade de somente a partir da figura, da extensão e do número serem definidos a substância e os acidentes que preenchem um corpo empírico.

\section{III}

Talvez o critério da dúvida seja insuficiente para se operar com as ciências empíricas, porque essas ciências, conforme vimos acima, têm de operar com os compostos, estando sempre marcadas pela contingência da experiência. A dúvida se opõe à certeza, e esta, por sua vez, é precisamente definida em Descartes, na esfera metafísica, como irmã congênita da evidência. Assim, quando esta nasce, aquela já se manifesta conjuntamente. Mas, se em Descartes há uma teoria bem precisa da certeza, é preciso ainda saber se também há uma teoria bem constituída da dúvida. Conquanto a dúvida presida o percurso da I Meditação, aí ela é definida negativamente pela ausência de graus de certeza. Mas isso é da ordem do que se constata, ou seja, na I Meditação não sabemos ainda por que a dúvida se manifesta, nem quais representações lhe dão ensejo, nem que mecanismos produzem esse ato no intelecto. ${ }^{6}$

\footnotetext{
${ }^{6}$ Não se ignora aqui o fato de que a dúvida faz parte de um projeto maior de fundação absoluta do conhecimento, e de que Descartes tem esse projeto sempre presente sob sua visão. Faz parte desse projeto a intenção de que a dúvida seja deliberada, mas é importante frisar que ela resulta de uma decisão metodológica, e tem de assim fazê-lo, porque ainda não há nenhum critério para determinar precisamente a matéria do dubitável. J.-L. Poirier comenta: “A dúvida é aqui apenas um meio. Ela retira sua energia de uma vontade de verdade, ela não é conclusão de uma ignorância que não se aceita mais, mas resolução de duvidar" (1987, p. 100). Gueroult atesta, no mesmo sentido: "A dúvida metódica e sistemática [...] procede não das coisas, mas da resolução de duvidar [...]" (1968, p. 40). Ou seja, se na I
} 
Paradoxalmente, talvez possamos encontrar uma teoria bem constituída da dúvida na III Meditação, se entendermos a dúvida não como resultado inacabado da operação do juízo, mas como déficit que ocorre no âmbito da ideia. Ou seja, aí, diferentemente do que ocorre na I Meditação, podemos investigar a gênese da dúvida no tocante aos juízos de existência. Mas qual seria o caminho para se proceder a essa investigação?

Como na altura da III Meditação, Descartes ainda se encontra absolutamente sozinho no mundo, pois ainda não descobriu se possui um corpo físico, se há um mundo externo e se esse Deus enganador pode representar de fato alguma realidade além do que hipoteticamente ouviu dizer, é forçoso então que procure algum meio para detectar outra existência além do cogito. Como os pensamentos são a única coisa de que dispõe até esse momento, passa então a examiná-los, com o intuito de romper o domínio do cogito e alcançar a realidade de algum outro existente. Como seria dispersivo examinar todos os conteúdos que atravessam o pensante, Descartes propõe-se então a fazer uma classificação dos pensamentos. No parágrafo sexto, afirma: "Alguns desses pensamentos são como imagens das coisas e somente a eles convém propriamente o nome de idéia [...]" (AT, VII, p. 37 - FC, III Méd., §6). $\mathrm{Na}$ sequência, Descartes acrescenta ainda ao gênero pensamento (cogitaciones) as seguintes espécies: volições (quando quero), afecções (quanto temo) e juízos (quando afirmo e nego). Descartes passa então a examinar imediatamente essa classificação, para saber em quais espécies assim circunscritas “[...] reside propriamente a verdade e a falsidade" (AT, VII, p. 37 - FC, III Méd., §5). Para proceder a esse exame, faz a seguinte observação:

Meditação ainda não há uma teoria do que constitui a certeza, também não pode aí haver uma teoria acerca da deficiência que constitui o dubitável. Desse modo, se o trajeto dubitativo precede a teoria das ideias, ele tem de ser conduzido não por um saber, mas por um pressuposto exclusivamente metodológico. 
Agora, no que se refere às idéias, se consideradas em si mesmas e não referidas às coisas a que se reportam, não podem ser propriamente falsas. Pois, quer imagine uma cabra ou uma quimera, não é menos verdadeiro que imagino tanto uma quanto a outra. E, também, não há que temer falsidade alguma na própria vontade ou nos afetos, pois, embora eu possa almejar coisas más ou até coisas que não se encontram em parte alguma, não é por isso menos verdadeiro que as almejo (AT, VII, p. 37 - FC, III Méd., §7 e 8).

É bastante difícil, para um leitor exigente, entender o uso das palavras "verdadeiro" e "falso" nessa passagem, pois, uma vez suprimidas as coisas às quais os pensamentos se reportam, parecem também suprimidas quaisquer condições para uma teoria da verdade. No entanto, Descartes inverte as condições de remissão, e por uma suspeição típica e generalizada entre os modernos, advoga que a realidade de uma ideia é previamente marcada pela atividade do cogito, que se constitui como um fundamento imediato de representações. Descartes concebe isso como uma realidade material das ideias, porque ela designa a força do pensante para conceber quaisquer ideias em sua mente, independentemente da realidade externa a que essas ideias possam se reportar. Portanto, enquanto modos - para aqui utilizarmos a linguagem cartesiana -, todos os nossos pensamentos são indistintamente verdadeiros, se estou certo de que os concebo em minha mente. ${ }^{7}$ O problema da teoria da verdade, no entanto, se inverte quando eu verticalizo a relação contraída pelos conteúdos do

\footnotetext{
${ }^{7}$ Este problema está bem descrito por R. Glauser, quando afirma: "Em suma, por idéia, tanto Descartes compreende um modo complexo do pensamento composto de uma realidade material, o ato, e de uma realidade objetiva, que é o objeto ou o conteúdo deste ato, quanto ele restringe a significação do termo idéia e aplica-o unicamente à realidade objetiva; a idéia, nesse último sentido, é então tratada como um objeto" (1999, p. 66). Esse duplo sentido do termo idéia, em Descartes, possibilita que ora ele seja remetido ao próprio pensante, ora seja remetido às coisas externas ao cogito. O pressuposto dessa dúplice remissão forma um jogo semântico um tanto complexo, que permite a Descartes fazer dois usos do termo verdade, sem avisar ao leitor, em cada caso, de que uso se trata.
} 
pensamento, e me pergunto quais desses pensamentos podem me remeter para fora do pensante. As volições e afecções não podem cumprir essa tarefa, pois expressam o modo como o pensante toma consciência das representações que se manifestam na mente. Já o juízo está estreitamente vinculado com a teoria da verdade, porque embora seja um ato mental, ele executa o conteúdo representativo de uma ideia. Na teoria da ideia, portanto, se encontra o fundamento último da teoria da verdade. Descartes afirma que elas são como imagens das coisas, e isso quer dizer que somente através do exame delas eu poderei resolver o problema da remissão e da exterioridade.

Mas além de haver uma dupla remissão na teoria das ideias, pois elas se reportam tanto ao pensante quanto a uma realidade externa, há ainda uma intersecção, na teoria das ideias, entre teoria da causalidade e teoria da perfeição. Do ponto de vista da teoria da causalidade Descartes afirma que a ideia contém, por similitude, uma parte da realidade da coisa à qual se reporta. À presença de algo por similitude na ideia Descartes denomina realidade objetiva; à coisa à qual essa realidade objetiva se reporta Descartes denomina realidade formal. Descartes afirma:

Mas, que essa idéia contenha esta e não aquela realidade objetiva, deve-o ela seguramente a alguma causa da qual a recebeu e na qual há no mínimo tanta realidade formal quanto essa idéia contém de realidade objetiva. Pois, se supusermos que há na idéia algo que não havia em sua causa, ela o teria obtido, portanto, do nada. E, por mais imperfeito que seja esse modo de ser pelo qual a coisa, mediante idéia, é objetivamente ou por representação no intelecto, é seguro, no entanto, que ele não é totalmente um nada e não pode, por conseguinte, provir do nada. (AT, VII, p. 41 - FC, III Méd., §18).

Aqui percebemos claramente a intersecção entre teoria da causalidade e teoria da perfeição. Como cópia, a ideia sempre porta consigo uma realidade objetiva, recebida por graus de representação de alguma realidade formal. Descartes aqui opera com a hipótese semântica do que 
poderíamos chamar de um realismo criacionista: todo o ser deriva em última instância de uma realidade formal, que é sustentada, em seu fundamento último, por um ato da substância infinita. Assim, principiando da realidade suprema e passando pelas substâncias extensas e pensantes, pelos modos, até atingir, no extremo oposto, os acidentes, há uma infinita gradação de graus de perfeição que constituem a estrutura ontológica de todos os existentes. Portanto, a teoria do déficit é inerente à concepção metafísica cartesiana e pode ser lida num dúplice sentido. De um lado, ela percorre os existentes no eixo horizontal, na medida em que a realidade atual ou formal de cada um é constituída diferentemente pelos graus de perfeição que possuem. De outro lado, ela se manifesta no eixo vertical, na medida em que ocorre nova gradação entre a realidade formal e sua participação por graus de representação na ideia, de tal modo que as ideias de substância contêm mais realidade objetiva do que as ideias de modos e acidentes, e a ideia de substância infinita contém mais graus de ser do que as ideias de substâncias finitas. ${ }^{8}$ Descartes ressalta claramente

${ }^{8}$ Há uma detalhada exegese de J.-M. Beyssade (1997, p. 11-36-publicada inicialmente na Revue Internationale de Philosophie, v. 50, n. 195, 1/1996, ) da teoria cartesiana da substância, que bem retrata o que aqui foi denominado de eixo vertical. Tomando como principal referência os parágrafos 51 a 54, da Primeira Parte dos Princípios da Filosofia (AT, IX-2, p. 46-48), o autor nos mostra que o termo substância tem de ser entendido em dois sentidos radicalmente distintos, na medida em que nos referimos a Deus (substância infinita), por um lado, e à coisa pensante e à coisa extensa (substâncias finitas), por outro. J.-M. Beyssade comenta: “O termo ,substância., nas Meditações, convém ao mesmo tempo à alma, ao corpo e a Deus; mas ele não se deixa ser conduzido, nesse texto, à univocidade [...]" (1997, p. 23) (grifo nosso). Acerca desse problema, argumenta o autor: "Não é preciso, então, transgredir a substância para aceder à infinitude; a substância não é, pela sua natureza, indiferente à infinitude ou à finitude e, menos ainda, ela é, por essência, substância finita. E Deus não está para além da substância, o que se chamava, na Escola, suprasubstância. As substâncias finitas é que seriam antes infra-substâncias, se o neologismo nos é permitido" (BEYSSADE, 1997, p. 23). Percebemos, claramente, como a teoria da substância está vinculada à teoria da perfeição, e como isso gera uma verticalização do problema ontológico. A teoria dos existentes permeia os acidentes, os modos, as substâncias finitas e tem de reportar-se, finalmente, à 
o caráter deficitário da realidade objetiva, que sempre acolhe de modo imperfeito, ou seja, por graus de representação, uma realidade formal no intelecto.

Toda realidade objetiva, por conseguinte, se assenta fundamentalmente em uma teoria do déficit, porque sempre depende, seja no eixo horizontal seja no eixo vertical, de uma causa que possui mais graus de perfeição do que seu efeito. No eixo vertical, a realidade objetiva é uma realidade adquirida por graus de representação. Desse modo, há uma semântica do déficit, na medida em que somente tem valor cognitivo a ideia que, por graus de representação, guarda alguma similitude com ou se reporta a alguma realidade formal. A tese da ideia como cópia já é uma tese sobre a sua dependência semântica de uma realidade formal. Desse modo, a proposição de que uma ideia não possa não "provir do nada" significa, em Descartes, que essa ideia tem de alcançar, por graus de representação, uma realidade formal como sua referência última.

A dúvida, portanto, é um ato inerente às operações do intelecto. Nem sempre a atenção e a não precipitação poderão evitá-la ou suprimila. Pelo contrário, muitas vezes terão de reivindicá-la como único e irremediável recurso para evitar o erro. Na medida em que o intelecto não pode, por suas próprias forças, agregar mais realidade objetiva às ideias que considera muito deficitárias em graus de representação, o único recurso possível é recusar-se a executar o conteúdo representativo de uma ideia, ou seja, suspender o juízo que a requer. Desse modo, em uma teoria que se funda no método dos matemáticos, isto é, na ordem das razões, a dúvida permanece como procedimento de interdição, demarcando todos os terrenos impróprios para a travessia do método.

substância infinita. Por isso temos insistido no argumento de que em Descartes o problema ontológico esposa a forma de uma teoria do déficit. Ou seja, exceptuandose Deus, a quem o termo substância pode ser aplicado em sentido pleno, todos os outros níveis ontológicos são definidos, gradualmente, pela menor ou maior ausência dos graus de perfeição. É este problema que se omite quando se supõe estabelecer uma correspondência ótima entre Física e Matemática só e simplesmente a partir da teoria do extenso. 


\section{IV}

O intrincado modelo metafísico da III Meditação nos afasta por completo de qualquer modelo cognitivo platônico. Em Platão sempre remanesce a possibilidade última de contemplação teórica enquanto intuição da própria coisa que se apresenta ao olhar do intelecto, uma vez que a visão empírica pode ser o primeiro degrau de uma ascese, mas jamais conforma uma precondição do olhar intelectual. A solução cartesiana, com a divisão entre realidade formal e realidade objetiva (índice de perfeição por graus de representação) exclui por completo essa possibilidade. Descartes compreende a ideia sensível dos corpos externos dentro do cânon da composição: ela é uma cópia advinda dos sentidos, um retrato recuperado pelas sensações, sempre limitado em relação às propriedades genuínas do modelo que contém a realidade formal a que ela se reporta. Dos próprios alicerces do pensamento cartesiano, emerge uma mui teorizada resignação cognitiva, uma vez que Descartes sempre pressupõe esse modelo do decaimento dos graus de perfeição entre realidade formal e realidade objetiva.

O confronto entre o modelo matemático e o físico, depois das experiências de G. Galilei, apresenta dois mundos teóricos que não poderão mais se recobrir. Em face de toda a idealização platônica, a mecânica apresenta a possibilidade de uma ciência matemática dos fenômenos no âmbito dos fenômenos. Abre-se, portanto, a partir de G. Galilei, o problema do estatuto da fonte que recolhe as informações sobre o mundo empírico. Este problema do estatuto da percepção empírica está reproposto dentro da intrincada teoria cartesiana do conhecimento metafísico. As ideias matemáticas têm um grau acentuado de realidade objetiva, mas quando captam informações sobre o existente, traduzemnas imediatamente num índice só compreensível ao intelecto, divergindo por completo das cópias recolhidas pela visão e pelos outros órgãos dos sentidos. O problema constituído por Descartes está no déficit ontológico entre informação matemática e informação empírica, porque, por maior 
que seja a capacidade humana em transcrever o empírico no extenso, é sempre forçosa a reconversão do objeto matemático em empírico, para que ele seja projetado no espaço que se abre ao corpo próprio através dos sentidos.

Este problema acirra-se no decorrer das Meditações. Após atravessarmos a teoria do erro, na IV Meditação, parece que a chave da clareza está em evitar a precipitação. Mas quando esperamos, com este instrumento, encontrar sob a forte luminosidade das matemáticas, um outro mundo empírico, nos defrontamos com os sinais obscuros do corpo próprio, e percebemos que a matemática poderá penetrar pelos poros da imperfeição de nossa existência empírica, sem jamais poder suprir a deficiência ontológica instalada pelo corpo próprio. É como se a orientação inteligível, fornecida pela Matemática, fosse insoluvelmente insuficiente para conduzir uma mente que tem de deliberar, na maior parte do tempo, com a realidade objetiva de ideias advindas dos órgãos dos sentidos. Ou seja, o problema originário em Descartes, da separação entre coisa extensa e coisa pensante, ou da separação entre corpo e mente, se desdobra, na sequência, no problema do acesso do pensante ao mundo empírico. ${ }^{9} \mathrm{Na}$

\footnotetext{
${ }^{9}$ D. Garber (1992, p. 63-93) constrói três argumentos para examinar esse problema, considerando ser o terceiro o mais exitoso. Segundo Garber, o fio condutor do principal argumento encontra-se na decisiva conclusão que Descartes quer estabelecer, ou seja, “[...] que os corpos que existem objetivamente em nossa mente e formalmente fora da nossa mente são somente objetos geométricos, coisas das quais nós podemos estar certos de excluir as qualidades sensoriais não-geométricas que os não-iniciados são inclinados a atribuir aos corpos" (1992, p. 84). D. Garber continua: "A estratégia de Descartes para estabelecer isso é afirmar que nós podemos clara e distintamente conceber a mente, o sujeito do pensamento, como descoberta na II Meditação, independentemente do corpo, e o corpo, concebido como um objeto contendo somente propriedades geométricas, independentemente da mente (ver AT, VIII, p. 78). Se isto pode ser estabelecido, então ele pode apelar à onipotência divina para estabelecer que mente e corpo são genuinamente distintos [...]" (1992, p. 85). O argumento é engenhoso, porque o corpo, enquanto suporte de propriedades geométricas, é plenamente acessível à mente distinta do corpo próprio. No entanto, a mente tem de se reportar, em última instância, a uma referência empírica que seja o suporte dessas propriedades geométricas. A solução apresentada por D.
} 
VI Meditação, comentando as dificuldades que apresentam essa conjunção, Descartes observa:

E facilmente entendo que, se existe algum corpo a que a mente esteja conjugada de maneira que, a seu arbítrio, a ele se aplique como que a inspecioná-lo, pode ser que eu imagine por isso mesmo as coisas corporais. De sorte que este modo de pensar só difere da intelecção pura porque a mente, ao entender, volta-se de certo modo para si mesma e repara em alguma das idéias que nela se encontram, ao passo que, ao imaginar, volta-se para o corpo e nele vê algo conforme a uma idéia que ou é entendida por ela ou é percebida pelo sentido. Digo ser fácil entender que a imaginação possa atuar dessa maneira, desde que exista um corpo. E, porque não me ocorre nenhum outro modo tão apropriado quanto este para explicá-la, conjeturo por isso que o corpo provavelmente existe (AT, VII, p. 73 - FC, VI Méd., §4).

Descartes considera que a imaginação não constitui uma faculdade essencial do pensante, de tal modo que se ela “[...] estivesse ausente de mim, eu sem dúvida permaneceria o mesmo que agora sou" (AT, VII, p. 73 - FC, VI Méd., §4). Agora, se for assumido o pressuposto de que toda realidade objetiva provém de uma realidade formal, e se for aceito o fato de que eu imagino as coisas corporais, então se torna forçoso considerar a hipótese de que a mente esteja conjugada a um corpo próprio, que faz a mediação entre a imaginação e o mundo externo. Assim, na intelecção pura, a mente volta-se para si própria, mas se se propõe a

Garber é exclusivamente metafísica, produzindo, por isso, uma disfunção epistemológica. Ou seja, ela resolve o problema da correspondência entre a mente e as propriedades geométricas, mas não assegura que essa correspondência seja válida para os objetos empíricos, que têm de ser o suporte da correlação. Desse modo, essa solução produz a seguinte disfunção epistemológica: ela resolve os problemas da Física no interior da esfera da Matemática, uma vez que os objetos matematizados são plenamente acessíveis à mente, mas é incapaz de assegurar à Matemática o acesso ao mundo empírico. 
imaginar, ou tem de voltar-se para as imagens corporais retidas pelos sentidos, ou é forçada a aplicar ideias que encontrou em si mesma aos objetos captados por esses sentidos. Portanto, a imaginação e o corpo próprio são canais exclusivos de contato com o mundo externo. O problema cartesiano insolúvel é a localização do corpo humano, que força a teoria da verdade a se desdobrar em uma dúplice relação. Desse modo, ela terá de jungir a realidade objetiva captada pela imaginação à realidade objetiva inscrita no intelecto. Somente na intersecção desses dois modelos é que se pode fundamentar a Física, que terá de sempre enfrentar a dificuldade de ser uma ciência do composto.

O desdobramento da teoria da verdade em uma dúplice relação dá origem ao problema da adequação, que, conquanto pareça simples a um primeiro exame, pode ser entendido, em Descartes, como o problema da intrincada relação entre objeto empírico e intelecto. Em primeiro lugar, porque há a distinção ontológica entre realidade formal e realidade objetiva, mas a realidade formal é causa da realidade objetiva, sem, por isso, estar nela presente. Em segundo lugar, porque no tocante às ideias matemáticas, nós temos acesso a sua realidade objetiva, mas não conseguimos, por mais clara e evidente que seja a realidade objetiva, precisar qual seria o referente que comportaria sua realidade formal. Em terceiro lugar, porque não há uma teoria clara da correlação entre a realidade objetiva das ideias matemáticas e a realidade formal dos objetos empíricos. Acerca da correlação ontológica cruzada, há muito pouca coisa explícita em Descartes, porque não há nenhum modelo ontológico invertido, que explique o que aqui denominamos causalidade cruzada. Ou seja, no tocante aos objetos matemáticos e aos objetos empíricos, sabemos que há uma correlação causal direta entre a realidade formal e a realidade objetiva para cada esfera em separado de objetos. Mas no tocante à correlação ontológica invertida, não sabemos explicar como se constroem os pontos de contato 
entre a realidade objetiva das ideias matemáticas e a realidade formal dos objetos empíricos..$^{10}$

A Física, em Descartes, depende da disjunção entre alma e corpo, porque depende do contato entre duas regiões, doravante incongruentes: a das ideias matemáticas e a das supostas realidades corpóreas. Desse modo, é insuficiente determinar o domínio e o valor das ideias matemáticas (na V Meditação), se não conseguirmos circunscrever o contato do corpo próprio com a região da experiência. Pela própria disjunção entre realidade objetiva, realidade formal e realidade material das ideias, torna-se fundamental, em Descartes, circunscrever o nosso contato com o mundo exterior. Nesse sentido, o corpo próprio estabelece o elo que vincula o domínio das ideias inatas às substâncias corporais. Os nossos sentidos

${ }^{10}$ Os objetos empíricos possuem uma realidade formal que se converte em realidade objetiva ao serem recebidos como ideias em nossas mentes. Também as ideias matemáticas adquirem uma realidade objetiva em nossa mente, possuindo um excelente grau de correspondência com a suposta realidade formal dos objetos matemáticos. Isso nos é assegurado pela maneira clara e distinta como conseguimos conceber essas ideias em nossa mente. O problema surge quando tentamos converter essa certeza matemática subjetiva em conhecimento físico acerca do mundo externo. Comentando esse problema, Popkin (1979, p. 205-207) reporta-se ao que na Lettre de Monsieur Des-Cartes à Monsieur C. R. L. (AT, IX-1, p. 211-212), Descartes denominou de "objeção das objeções", resumindo-a com os seguintes argumentos: "Vários excelentes espiritos [...] crêem ver claramente que o extenso Matemático, o qual eu ponho como o princípio de minha Física, não é outra coisa senão meu pensamento, e que ele não tem e nem pode ter nenhuma subsistência fora do meu espirito, sendo apenas uma abstração que eu faço do corpo Físico; e, portanto, que toda a minha Física somente pode ser imaginária e fictícia, como são todas as Matemáticas puras; e que, na Física real das coisas que Deus criou, é preciso [haver] uma matéria real, sólida e não imaginária" (AT, IX-1, p. 212) (o grifo é de Descartes). Popkin observa que “a resposta de Descartes à „objeção das objeções. consiste em destacar as terríveis conseqüências que se seguiriam se nós a tomássemos seriamente" (1979, p. 206). No entanto, as consequências são justamente as céticas. Se considerarmos que Descartes se recusa a apreciar essa objeção a partir dos fundamentos de sua própria teoria, defendendo-os e mostrando sua consistência, e que enfrenta essa objeção a partir das consequências terríveis que adviriam da suposta insuficiência desses fundamentos, poderemos estimar a força e a extensão dessa objeção, da qual o autor estava bastante consciente. 
são vias redutivas, que convertem as coisas corpóreas em imagens sensíveis. Essas imagens sensíveis, no entanto, são deficitárias do ponto de vista da relação entre realidade formal e realidade objetiva. Esse déficit se torna importante porque circunscreve o domínio da Física, sempre marcado pela interposição dos sentidos. Na VI Meditação, Descartes observa:

É verdade que costumo imaginar muitas outras coisas, além dessa natureza corporal que é objeto da Matemática pura, como cores, sons, sabores, dor e coisas semelhantes, nenhuma, porém, tão distintamente quanto ela. E, porque as percebo melhor pelo sentido, parece que foi por ele e por obra da memória que chegaram à imaginação. De modo que, para dispensar-lhes um tratamento mais apropriado, é conveniente cuidar igualmente do que seja sentir, examinando se, a partir das coisas percebidas por esse modo de pensar que chamo sentir, posso obter algum argumento certo em favor da existência das coisas corporais (AT, VII, p. 74 - FC, VI Méd., §5).

Descartes propõe-se a discutir o estatuto do sentir, para examinar a correlação que nossos pensamentos podem estabelecer com as coisas corporais. Novamente se repõe o tema da dificuldade de acesso ao mundo exterior. Esse tema constitui a bússola e o fio de Ariadne metafísico da VI Meditação, que funda-se numa incongruência ontológica: descobre-se que os corpos existem (a partir dos atributos metafísicos que compõe necessariamente a essência de Deus), no entanto, para nós homens, por nossa essência, eles somente podem ser detectados como um conjunto de afecções do corpo próprio.

Descartes retorna assim a um tema de teodiceia (é mais útil e indica maior perfeição que o corpo próprio seja assim e não de outro modo), mas não se aproxima daquilo que, a essa altura, mais nos inquietaria: como assegurar que a Matemática seja o fundamento da Física, ou seja, que a ontologia das ideias matemáticas seja o fundamento dos entes da filosofia da natureza? A VI Meditação apresenta uma teoria das sensações, 
mas não uma teoria que correlacione empiria e extensão. Ter-se-ia a expectativa de que Descartes explicitasse os fundamentos da Física, enquanto, por um desvio (ontológico) fecundo e impensável, que lhe subtrai o confronto com os incontornáveis objetos empíricos, ele descobre o corpo próprio.

Mas por que o corpo próprio tem tanta força para se interpor? Possivelmente porque o preço a ser pago por uma solução de fundamentação absoluta da Matemática é tão excessivo, que o resíduo da dúvida hiperbólica perdura de modo ineliminável na VI Meditação. E se há algum recurso para superá-la, esse somente pode ser obtido por um procedimento metafísico. Assim, sem a existência de Deus (do Deus veraz), não há como resolver o problema da dupla remissão em dois níveis ontológicos:

a) o nível das ideias sensíveis que devem remeter a objetos sensíveis existentes;

b) o nível das ideias matemáticas que devem remeter à essência (propriedades geométricas) de objetos sensíveis existentes.

É em virtude desse problema da dupla relação, que Descartes não pode ocupar-se somente da fundamentação metafísica das ideias matemáticas. Pois, se somente elas estiverem fundadas metafisicamente, elas podem ser verdadeiras enquanto modos e enquanto essências, mas podem ser aplicadas a objetos supostamente sensíveis que não existem. Ou seja, a substancialidade das coisas materiais tem de estar assegurada metafisicamente para que a Física possa existir. Se isto ocorre é porque há uma incongruência ontológica entre o extenso e o preenchimento empírico. É essa incongruência que impossibilita indefinidamente que os objetos sejam conhecidos assim como eles são. De um lado, eu recebo ideias sensíveis, cuja realidade objetiva é sempre deficitária em relação à realidade formal da coisa dada. De outro lado, eu tenho ideias matemáticas, cuja realidade objetiva é excelente em relação ao preenchimento empírico da percepção, e pode ainda ser, além disso, rigorosamente adequada à realidade formal do objeto matemático. 
Isso ocorre em virtude de um desnível ontológico. As ideias sensíveis dependem da realidade formal da coisa dada empiricamente e do déficit inevitável da captação dos sentidos. As ideias matemáticas, por sua vez, não apresentam o déficit originário da aquisição, uma vez que são inatas, ou seja, remetem-se à realidade formal dos objetos matemáticos. Nesse sentido, é mínimo o déficit entre a realidade formal dos objetos matemáticos e a realidade objetiva presente nas ideias matemáticas. Como a realidade objetiva das ideias matemáticas possui um índice cognitivo muito superior ao das ideias sensíveis, cuja realidade objetiva é sempre deficitária em decorrência da apreensão dos sentidos, ocorre então que a Matemática torna-se assim um excelente índice cognitivo de um objeto empírico, do qual ela não pode, contudo, assegurar a existência

\section{V}

A VI Meditação, portanto, trata o tema da possível união entre mente e corpo como um tema de teodiceia, que se justifica pela sua utilidade para o corpo próprio. Desse modo, Deus não assegura o conhecimento claro e distinto do composto enquanto composto, porque o composto depende da junção de mente e corpo e da congruência entre o extenso e o empírico, ou seja, depende, em qualquer caso, da informação deficitária dos sentidos.

A distinção real entre corpo e mente é consequente, em Descartes, com a fundamentação absoluta da Matemática, única ciência que o filósofo consegue definire fundamentar rigorosamente. Se não houvesse a separação real entre corpo e mente, o mundo mental seria formado, na melhor das hipóteses, por cópias imagéticas do mundo empírico, podendo, como em Hobbes, ser objeto de cálculo racional feito com números ou com as operações da linguagem, mas a aplicação da matemática ao extenso jamais transportaria para o empírico uma sobreobjetividade, como ocorre em Descartes. Vê-se, portanto, que a distinção real da mente e do corpo, em Descartes, funda rigorosamente a Matemática e deficitariamente a Física. 
Em virtude da interposição dos sentidos e das imagens sensíveis, há uma incontornável incongruência entre os planos da Matemática e da Física.

Por esse mesmo motivo, somente através de Deus podemos nos certificar da existência das substâncias materiais, pois jamais podemos nos certificar disso mediante os recursos perceptivos do corpo próprio. As extremidades dos órgãos dos sentidos captam, na melhor das hipóteses, sequências de sensações, incapazes de nos informar sobre a realidade externa das substâncias corporais. Com exceção do cogito e das ideias matemáticas, a cujas realidades temos acesso imediatamente, a fundamentação da Física ocorre mediante certezas metafísicas, às quais só podemos ter acesso mediatamente e por recursos conceituais. Ou seja, o mundo das substâncias corpóreas externo a nossas sensações é inalcançável para o corpo próprio, e somente pode tornar-se objeto de procedimentos científicos pelo recurso às certezas metafísicas. Assim, por uma espécie de platonismo sem transcendência ou recurso ao inteligível, a Física cartesiana está condenada a examinar deficitariamente as coisas corporais mediante a realidade captada pelos sentidos

\section{REFERÊNCIAS}

BEYSSADE, Jean-Marie. A teoria cartesiana da substância. In: Analytica. Rio de Janeiro. v. 2. n. 2. p. 11-36, 1997.

DESCARTES. Oeuvres de Descartes. Editadas por Charles Adam e Paul Tannery. Paris: Vrin, 1996. v. VII e IX.

. Meditações sobre Filosofia Primeira. Edição bilíngue. Tradução e nota prévia de Fausto Castilho. Campinas/SP: Editora da Unicamp, 2004.

GARBER, Daniel. Body: its existence and nature. In: . Descartes' metaphysical physics. Chicago: The University of Chicago Press, 1992. p. 63-93.

GLAUSER, Richard. Descartes et 1.héritage cartésien. In: 
Berkeley et les philosophes du XVIIe siècle. Perception et scepticisme. Liège: Pierre Mardaga Editeur, 1999. p. 33-100.

GUEROULT, Martial. Descartes selon l'ordre des raisons. Paris: AubierMontaigne, $1968.2 \mathrm{v}$.

POIRIER, Jean-Louis. Commentaire. In: DESCARTES. Les Méditations Métaphysiques. Edição preparada por J.-L. Poirier. Paris: Bordas, 1987. p. 95-190.

POPKIN, Richard H. Preface; Descartes: conqueror of skepticism (cap. IX); Descartes: sceptique malgré lui (cap. X). In: . The History of Scepticism from Erasmus to Spinoza. Berkeley and Los Angeles: University of California Press, 1979. Preface, p. xiii-xxii; cap. IX, p. 172192; cap. X, p. 193-213.

Data de registro: $18 / 07 / 2011$ Data de aceite: 24/08/2011 